\title{
Porous Zeolitic Imidazolate Framework Loaded Mn as an Efficient Catalyst for the Selective Catalytic Reduction of $\mathrm{NO}_{x}$ with $\mathrm{NH}_{3}$
}

\author{
Yongliang Chen ${ }^{1}$, Meiqing $\mathrm{Yu}^{1,2}$, Rui Wang ${ }^{1^{*}}$ \\ ${ }^{1}$ School of Environmental Science and Engineering, Shandong University, Jimo, Qingdao \\ 266237, China \\ 2 Undergraduate School, Shandong University, Jinan 250199, China
}

\begin{abstract}
Zinc 2-methylimidazolate $\left(\mathrm{Zn}(\mathrm{Me}-\mathrm{Im})_{2}\right.$, ZIF-8) was synthesized through solvothermal method, and the Mn@ZIF-8 was synthesized by loading the Mn species onto the prepared ZIF- 8 through impregnation. The effect of the addition amount of $\mathrm{Mn}$ species on the activity in selective catalytic reduction of $\mathrm{NO}_{x}$ with $\mathrm{NH}_{3}\left(\mathrm{NH}_{3}-\mathrm{SCR}\right)$, the stability of catalysts at ideal temperatures and the resistance to $\mathrm{H}_{2} \mathrm{O}$ and $\mathrm{SO}_{2}$ were investigated. Moreover, the characterizations of the catalysts including XRD, SEM, EDS, XPS, BET, TGA and $\mathrm{H}_{2}$-TPR were carried out. The results indicated that SCR activity of the catalysts was related to the addition amount of Mn species, the Mn@ZIF-8(0.8) showed the best NO conversion of over $90 \%$ ranging from $225^{\circ} \mathrm{C}-400^{\circ} \mathrm{C}$ with good stability in a long-time test. Besides, the Mn@ZIF-8 showed a high resistance to $\mathrm{SO}_{2}$. The ZIF- 8 has a great potential to be an excellent support, and Mn@ZIF-8 is promising catalyst in SCR reaction.
\end{abstract}

Keywords: Nitrogen oxides, SCR, Zeolitic imidazolate framework, ZIF-8

\section{INTRODUCTION}

\section{OPEN ACCESS}

Received: August 14, 2021

Revised: September 10, 2021

Accepted: September 14, 2021

${ }^{*}$ Corresponding Author:

wangrui@sdu.edu.cn

\section{Publisher:}

Taiwan Association for Aerosol Research

ISSN: $1680-8584$ print

ISSN: 2071-1409 online

(C) Copyright: The Author(s). This is an open access article distributed under the terms of the Creative Commons Attribution License (CC BY 4.0), which permits unrestricted use, distribution, and reproduction in any medium, provided the original author and source are cited.

Nitrogen oxides $\left(\mathrm{NO}_{\mathrm{x}}\right)$, mainly $\mathrm{NO}$ and $\mathrm{NO}_{2}$, is a kind of common gaseous pollutant, and the removal of $\mathrm{NO}_{x}$ has long been a difficult problem in air pollution control. The sources of $\mathrm{NO}_{x}$ can be divided into two categories, one is the mobile sources and the other is the fixed sources. The fixed sources mainly refer to the flue gas emitted from the combustion of fossil fuels such as coal and oil in the process of industrial production, and the mobile sources are generally thought to be the exhaust gas emitted from automobile engine. With the rapid development of modern industrialization, a large amount of fossil fuels have been exploited and consumed, making the $\mathrm{NO}_{x}$ emitted into the atmosphere far exceed the carrying capacity and self-purification capacity of the atmospheric environment. $\mathrm{NO}_{x}$ brought severe harm to environment, such as the photochemical smog, acid rain and ozone holes. All these environmental pollution phenomena are related to the emission of $\mathrm{NO}_{x}$, and have a serious threat to our human beings. Consequently, it is essential to control the $\mathrm{NO}_{\mathrm{x}}$ in the atmosphere (Brandenberger et al., 2008; Busca et al., 2008; Forzatti, 2001; Twigg, 2007).

$\mathrm{NH}_{3}$-SCR has been proven to be the most effective technique for abatement of $\mathrm{NO}_{\mathrm{x}}$ (Chen et al., 2016). And the catalyst with high denitrification efficiency is the key of the SCR technique. So far, the SCR catalysts can be divided into the following categories according to their active components: noble metal catalysts (Li et al., 2010; Qi et al., 2004), metal oxides catalysts (Qi et al., 2003a; Wei et al., 2018; Shen et al., 2016) and molecular sieve catalysts (Brandenberger et al., 2008; Delahay et al., 2005; Gao et al., 2017). Though the commercial catalysts $\mathrm{V}_{2} \mathrm{O}_{5}-\mathrm{WO}_{3}\left(\mathrm{MoO}_{3}\right) / \mathrm{TiO}_{2}$ have been widely used, the defects like narrow temperature window and toxicity of vanadium pentoxide still exist (Yi et al., 2016). Hence, the novel catalysts with wide temperature window and environment-friendly properties is desirable. 
Manganese oxide $\left(\mathrm{MnO}_{\mathrm{x}}\right)$, a kind of transition metal oxide, has attracted great attentions due to its various labile oxygen species and high activity in $\mathrm{NH}_{3}-\mathrm{SCR}$ reaction (Wu et al., 2007). Min et al. (2007) prepared different types of $\mathrm{MnO}_{x}$ catalysts through a precipitation method, and got a high $\mathrm{NO}_{x}$ conversion for the SCR of $\mathrm{NO}_{x}$ with $\mathrm{NH}_{3}$. To enhance the performance of $\mathrm{MnO}_{x}$ catalyst, a series of doping species and supporter was applied. Peng et al. (2016) used Eu to modify $\mathrm{MnO}_{\mathrm{x}}$ catalyst to promote SCR activity, and the results showed that $\mathrm{MnEuO}_{\mathrm{x}}$ exhibited a high $\mathrm{NO}_{x}$ conversion in a wide temperature range of $150-400^{\circ} \mathrm{C} . \mathrm{CeO}_{2}$ was a another metal species used to improve the SCR activity of $\mathrm{MnO}_{x}$. Qi et al. (2003b, 2004) prepared mixed manganese and cerium oxides, and the $\mathrm{MnO}_{x}-\mathrm{CeO}_{2}$ was highly active in SCR reaction obtaining almost $95 \%$ NO conversion at $150^{\circ} \mathrm{C}$. Singoredjo et al. (2010) prepared the alumina supported $\mathrm{MnO}_{x}$ exhibiting a high $\mathrm{NO}_{x}$ conversion during $120-300^{\circ} \mathrm{C}$. $\mathrm{TiO}_{2}$ is another kind of support commonly used to facilitate the SCR activity of $\mathrm{MnO}_{x}$, Park et al. (2013) loaded $\mathrm{Mn}$ on synthesized $\mathrm{TiO}_{2}$ through impregnation method, exhibiting a high NO conversion of almost $100 \%$ at $150^{\circ} \mathrm{C}$. Besides, a series of metal species such as $\mathrm{Fe}, \mathrm{Ce}, \mathrm{V}, \mathrm{Sm}, \mathrm{Zr}$, were used to modify the $\mathrm{MnO}_{\mathrm{x}} / \mathrm{TiO}_{2}$ to avoid poor resistance to $\mathrm{SO}_{2}$ of $\mathrm{MnO}_{x}$. Yet, the result could not meet the requirements of industrialization, further investigation is still needed (Yang et al., 2016; Niu et al., 2016; Zhang et al., 2018; Sun et al., 2018).

Metal organic frameworks (MOFs), the porous crystalline materials, have drawn extensive research interests due to their higher specific surface area, higher porosity, and more stable porous structure compared to the metal oxides (Lee et al., 2009). It is advantageous for them to adsorb the reactants and provide great gas storage, separation and catalysis, besides, the high specific surface, well ordered porous structure, and regular crystal structure have proven the MOFs to be ideal support (Zhang et al., 2016; Wang et al., 2016; Zhang et al., 2017). Zhang et al. (2017) loaded Mn and Ce onto MOFs through in situ and impregnation methods, and studied their catalytic activities in SCR reaction, the results showed that MnCe@MOF had a high $\mathrm{NO}_{x}$ conversion in a wide temperature range. Wang et al. (2016) prepared the $\mathrm{CeO}_{2} / \mathrm{MIL}-100(\mathrm{Fe})$ catalysts by encapsulating ceria nanoparticles into MIL-100(Fe) through impregnation, the $\mathrm{CeO}_{2} / \mathrm{MIL}-100(\mathrm{Fe})$ catalyst showed a high $\mathrm{NH}_{3}-\mathrm{SCR}$ activity and great resistance to $\mathrm{SO}_{2}$ at $196-300^{\circ} \mathrm{C}$. Zeolitic imidazolate framework (ZIFs), a sort of MOFs, has higher specific surface area and better thermal stability than ordinary MOFs (Huang et al., 2010; Park et al., 2006). Among them, ZIF-8 is the most widely studied ZIFs with a specific surface area of $1400 \mathrm{~m}^{2} \mathrm{~g}^{-1}$ and great thermal stability (Park et al., 2006; Venna et al., 2010), and has been widely used in gas adsorption, hydrogen storage and catalysis. However, few researchers have applied ZIF-8 in $\mathrm{NH}_{3}$-SCR reaction (Banerjee et al., 2008; Küsgens et al., 2009; Nguyen et al., 2012).

In this work, ZIF-8 was synthesized through a solvothermal method, and $\mathrm{MnO}_{\mathrm{x}}$ was firstly loaded on ZIF-8 by impregnation. The activity of the catalysts in $\mathrm{NH}_{3}$-SCR reaction, the stability of the catalysts, the effect of the addition amount of Mn species on catalytic activity as well as the resistance to $\mathrm{H}_{2} \mathrm{O}$ and $\mathrm{SO}_{2}$ were investigated. Besides, the characterization of the catalysts including XRD, SEM, EDS Mapping, XPS, BET, and $\mathrm{H}_{2}$-TPR, TGA was carried out to research the catalysts for further information.

\section{EXPERIMENTAL}

\subsection{Materials}

All the chemicals were available commercially and used without further purification. 2methylimidazole (2-HMelM, 99\%) Zinc nitrate Hexahydrate $\left(\mathrm{Zn}\left(\mathrm{NO}_{3}\right)_{2} \cdot 6 \mathrm{H}_{2} \mathrm{O}, 99 \%\right)$ were purchased from Tianjin Kemiou Chemical Reagent Co., Ltd. N,N-Dimethylformamide (DMF 99.5\%) and 50\% Manganese nitrate water solution $\left(\mathrm{Mn}\left(\mathrm{NO}_{3}\right)_{2}\right.$ 50\%) were purchased from Tianjin Fuchen Chemical reagents factory.

\subsection{Synthesis of Catalyst}

\subsubsection{Synthesis of ZIF-8 particles}

ZIF-8 was synthesized by solvothermal method according to the following procedure (Gee et al., 2013; Tran et al., 2011): A solid mixture of $\mathrm{Zn}\left(\mathrm{NO}_{3}\right)_{2} \cdot 6 \mathrm{H}_{2} \mathrm{O}(0.717 \mathrm{~g}, 2.41 \mathrm{mmol})$ and 2methylimidazole (H-MelM) $(0.18 \mathrm{~g}, 2.19 \mathrm{mmol}$ ) was dissolved in $50 \mathrm{~mL}$ DMF, the solution was 
transferred into a teflon-line stainless steel autoclave, and heated to $140^{\circ} \mathrm{C}$ at a rate of $5^{\circ} \mathrm{C} \mathrm{min}^{-1}$ in a temperature-programmed oven and maintained for $24 \mathrm{~h}$. After cooling to ambient temperature, the crystal was collected and washed with DMF for three times. Finally, these samples were dried at $60^{\circ} \mathrm{C}$ overnight to remove the residual solvents.

\subsubsection{Synthesis of Mn@ZIF-8}

The Mn was loaded on ZIF-8 via impregnation method reported by Zhang et al. (2017). Adding $0.4,0.6,0.8$, and $1 \mathrm{~mL}$ of $\mathrm{Mn}\left(\mathrm{NO}_{3}\right)_{2}$ respectively into $20 \mathrm{~mL}$ methanol to get $\mathrm{Mn}$ solutions, and dispersing $1 \mathrm{~g}$ of ZIF-8 into $30 \mathrm{~mL}$ methanol under ultrasonication for $15 \mathrm{~min}$ to get a ZIF-8 solution. Then, the Mn solution was slowly dropped into ZIF-8 solution under vigorous stirring for $4 \mathrm{~h}$, followed by filtration to get the precipitate, after that, the precipitate was dried overnight at $60^{\circ} \mathrm{C}$. Finally, the precipitate was heated at $300^{\circ} \mathrm{C}$ for $5 \mathrm{~h}$. The obtained samples were denoted as Mn@ZIF-8(0.4), Mn@ZIF-8(0.6), Mn@ZIF-8(0.8) and Mn@ZIF-8(1), respectively. For convenience, the Mn@ZIF-8 without note represents the Mn@ZIF-8(0.8).

\subsection{Characterizations of the Catalysts}

The XRD patterns were obtained on a Bruker D8 diffractometer using $\mathrm{Cu}$ K $\alpha$ radiation between $2 \theta=5^{\circ}$ and $45^{\circ}$. The micro-morphology of Mn@ZIF- 8 was investigated by scanning electron microscope (SEM) (SU 8010), and energy dispersive spectroscopy (EDS) mapping images were obtained on the same device. The X-ray photoelectron spectroscopy (XPS) analysis was carried on a Thermo Fisher Scientific ESCALAB 250 spectrometer, the correction of binding energy shift was referenced to $\mathrm{C} 1 \mathrm{~s}$ line at $284.6 \mathrm{eV}$, and the spectra of the $\mathrm{Mn} 2 \mathrm{p}$ and $\mathrm{O} 1 \mathrm{~s}$ were recorded. The specific surface area analysis was conducted on Micromeritics Tri Starll 3020 Surface Arae and Porosity Analyzer with a $\mathrm{N}_{2}$ adsorption, and the results were calculated with the multi-point Brunauer-Emmett-Teller (BET) approach. The thermogravimetric analysis (TGA) was carried on a TGA SDT Q600 thermogravimetric analyzer with a heating rate of $10^{\circ} \mathrm{C} \mathrm{min}^{-1}$ from $25^{\circ} \mathrm{C}$ to $600^{\circ} \mathrm{C}$ under nitrogen atmosphere. The hydrogen temperature programmed reduction $\left(\mathrm{H}_{2}-\mathrm{TPR}\right)$ analysis was performed in which $100 \mathrm{mg}$ of the samples were preheated to $450^{\circ} \mathrm{C}$ with a ramp rate of $10^{\circ} \mathrm{C} \mathrm{min}^{-1}$ under $\mathrm{N}_{2}$ atmosphere. After cooling to the ambient temperature, the samples were heated up to $800^{\circ} \mathrm{C}$ at a ramp rate of $8^{\circ} \mathrm{C} \mathrm{min}^{-1}$ with a flow of $\mathrm{H}_{2}$, and the consumption of $\mathrm{H}_{2}$ was continuously recorded using the TCD detector.

\subsection{Activity Tests}

The tests of $\mathrm{NH}_{3}-\mathrm{SCR}$ activity were carried out in a fix-bed quartz reactor ( $8 \mathrm{~mm}$ in diameter) heated by a tube furnace. The simulated flue gas contained $500 \mathrm{ppm} \mathrm{NO}, 500 \mathrm{ppm} \mathrm{NH}, 5 \% \mathrm{O}_{2}$, $3 \% \mathrm{H}_{2} \mathrm{O}$ (when used), 200 ppm SO 2 (when used) and balance $\mathrm{N}_{2}$, which were regulated by mass flow controllers respectively. In each run of SCR test, $0.2 \mathrm{~g}$ of Mn@ZIF-8 was used and the total flow rate was controlled at $100 \mathrm{~mL} \mathrm{~min}^{-1}$ corresponding to a gas hourly space velocity (GHSV) of approximately $240000 \mathrm{~h}^{-1}$. The catalyst was heated to the temperature ranging from $100^{\circ} \mathrm{C}$ to $450^{\circ} \mathrm{C}$ at a rate of $10^{\circ} \mathrm{C} \mathrm{min}^{-1}$, and held at each temperature spots for $50 \mathrm{~min}$. Concentrations of $\mathrm{NO}$ and $\mathrm{NO}_{2}$ were simultaneously monitored by the $\mathrm{NO}$ and $\mathrm{NO}_{2}$ analyzers (TH-9905), and $\mathrm{N}_{2} \mathrm{O}$ in the outlet gas was measured by an Antaris ${ }^{\mathrm{TM}}$ IGS Gas Analyzer from Thermo Fisher Scientific Inc. The $\mathrm{NO}_{\mathrm{x}}$ conversion rate and the $\mathrm{N}_{2}$ selectivity were calculated as follows:

$\mathrm{NO}_{\mathrm{x}}$ conversion $(\%)=\left(1-\frac{\left[\mathrm{NO}_{\mathrm{x}}\right]_{\text {out }}}{\left[\mathrm{NO}_{\mathrm{x}}\right]_{\text {in }}}\right) \times 100 \%$,

$\mathrm{N}_{2}$ selectivity $(\%)=\left(1-\frac{2\left[\mathrm{~N}_{2} \mathrm{O}\right]_{\text {out }}}{\left[\mathrm{NO}_{\mathrm{x}}\right]_{\text {in }}+\left[\mathrm{NH}_{3}\right]_{\text {in }}-\left[\mathrm{NO}_{\mathrm{x}}\right]_{\text {out }}-\left[\mathrm{NH}_{3}\right]_{\text {out }}}\right) \times 100 \%$

where the subscripts "in" and "out" refers to the inlet concentration and outlet concentration at steady state, respectively. 


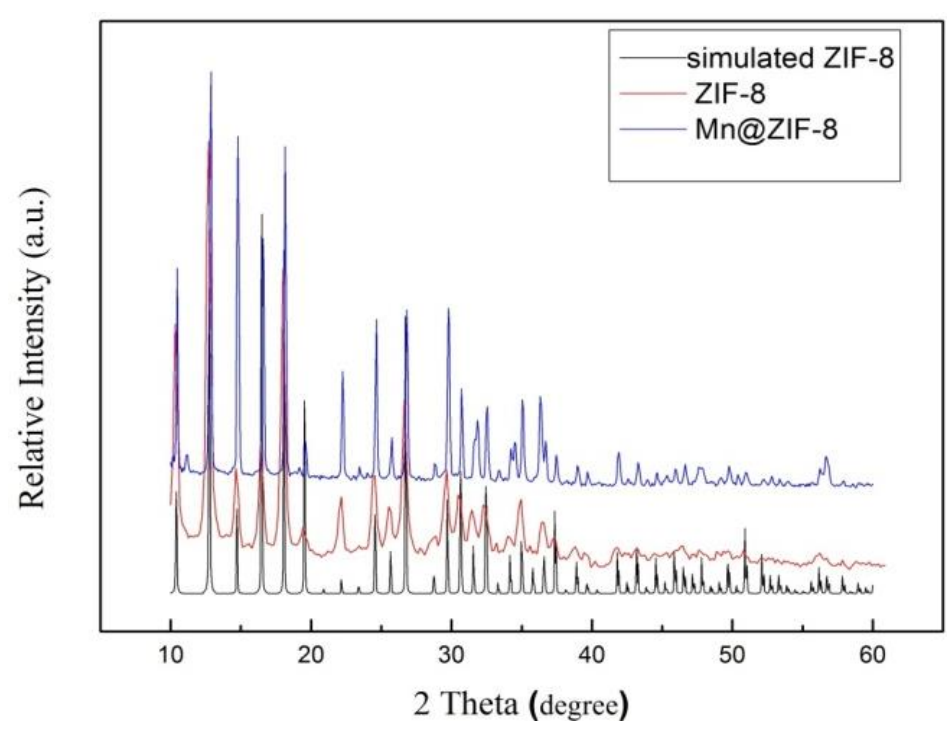

Fig. 1. XRD patterns of the catalysts.

\section{RESULTS AND DISCUSSION}

\subsection{Characterizations of the Catalysts}

\subsubsection{XRD}

To determine the crystal structure of the catalysts, the XRD analysis of the synthesized ZIF-8 and Mn@ZIF-8 was carried out. It could be easily seen from Fig. 1 that the characteristic peak of synthesized ZIF-8 was in accordance with the simulated ZIF-8, which approved the ZIF-8 was successfully synthesized. As for the XRD pattern of Mn@ZIF-8, no apparent difference was found after the impregnation, indicating that the crystalline structure of ZIF-8 retained well. Yet, the characteristic peaks of $\mathrm{Mn}$ species were not observed which may be interpreted by that the Mn species were in amorphous phase (Li et al., 2017).

\subsubsection{SEM and EDS Mapping}

SEM was carried to investigate the structure of Mn@ZIF-8. It can be seen from Fig. 2 that the synthesized catalysts still retained its dodecahedral shape, which matched well with the results of XRD analysis. Moreover, EDS Mapping was performed to demonstrate the distribution of Mn, $\mathrm{Zn}$ species, and it could be seen that the elements of $\mathrm{Mn}$ and $\mathrm{Zn}$ are uniformly distributed on the whole surface of the catalysts, which was beneficial for adsorption and activation of the reactants, and was conducive to the $\mathrm{NH}_{3}-\mathrm{SCR}$ catalytic activity.

\subsubsection{XPS spectra}

To further investigate the chemical state of Mn elements in the catalysts, XPS spectra were recorded and displayed in Fig. 3(a), from which it could be seen obviously that two prominent peaks at $642.89,654.73 \mathrm{eV}$ accompanied by two satellite peaks at 641.53, $653.46 \mathrm{eV}$ were gained after fitting by Gaussian components. The peaks at $641.53 \mathrm{eV}, 653.46 \mathrm{eV}$ could be attributed to $\mathrm{Mn}^{2+}$ species, while the peaks at $642.89 \mathrm{eV}$ and $654.73 \mathrm{eV}$ could be assigned to $\mathrm{Mn}^{3+}$ (Becerra et al., 2011; Guo et al., 2016). According to previous reports, the co-existence of $\mathrm{Mn}^{2+}$ and $\mathrm{Mn}^{3+}$ on the catalysts could facilitate the formation of oxygen vacancies, which played an important role in low temperature oxidation property (Liu et al., 2012). Besides, the high valence state of $\mathrm{Mn}^{3+}$ species would improve the reducibility of the sample (Cheng et al., 2017).

The 0 1s XPS spectra of the Mn@ZIF-8 were shown in Fig. 3(b), two asymmetric peaks could be observed, indicating there were two distinct types of oxygen species. The lower binding energy peak at $530.27 \mathrm{eV}$ was ascribed to the lattice oxygen species $\mathrm{O}^{2-}$ in the catalysts, and the sub-bands at $531.71 \mathrm{ev}$ was attributed to surface chemisorbed oxygen species, such as $\mathrm{O}^{2-}$ or $\mathrm{O}^{-}$(Atribak et al., 2011). 

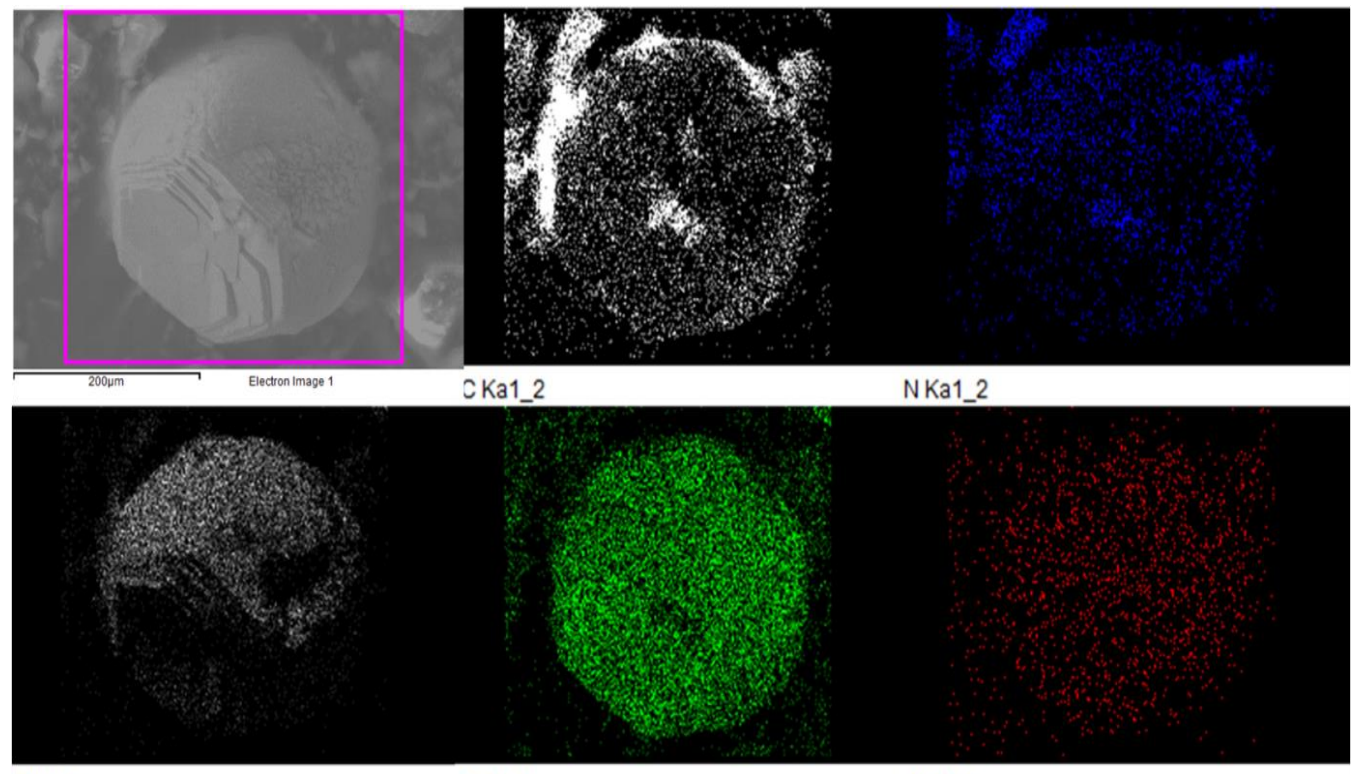

OKa1

Zn Ka1

Un Ka1

Fig. 2. SEM image and EDS Mapping of Mn@ZIF-8.
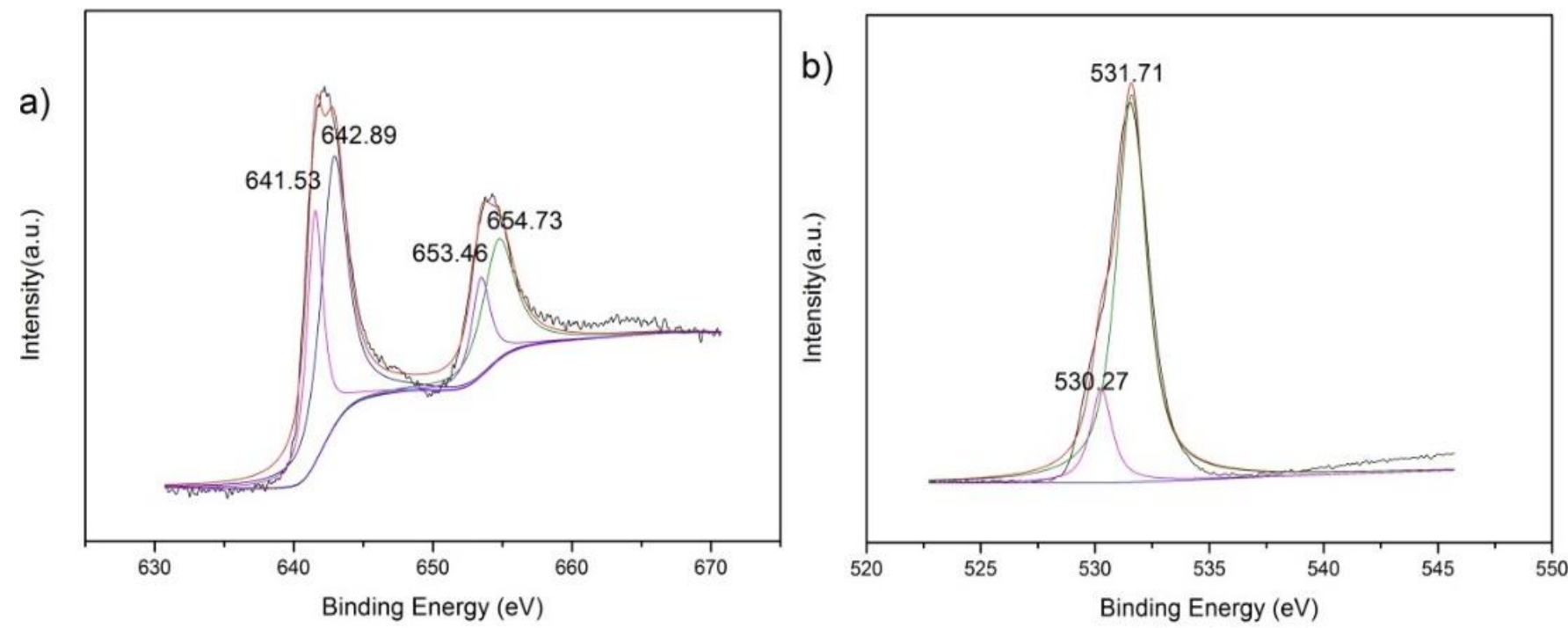

Fig. 3. XPS spectra of (a) Mn 2p and (b) O 1s for Mn@ZIF-8.

\subsection{4 $\mathrm{H}_{2}$-TPR}

To investigate the redox behavior of Mn@ZIF-8, the $\mathrm{H}_{2}$-TPR analysis was performed, and the results were presented in Fig. 4, from which it could be seen that there are two main reduction peaks. The first peak located at around $250^{\circ} \mathrm{C}$ could be assigned to the reduction of $\mathrm{MnO}_{2}$ to $\mathrm{Mn}_{2} \mathrm{O}_{3}$ and the following peak around $520^{\circ} \mathrm{C}$ could be attributed to the further reduction of $\mathrm{Mn}_{2} \mathrm{O}_{3}$ to $\mathrm{MnO}$ (Zhao et al., 2016; Du et al., 2018). Normally, the operational temperature should be lower than $450^{\circ} \mathrm{C}$. This prominent peak could be caused by the reduction of $\mathrm{Mn}^{3+} \rightarrow \mathrm{Mn}^{2+}$ and the decomposition of ZIFs based on the TGA curves. Then, it could be speculated that the doping of $\mathrm{Mn}$ species prompted the catalysts to have the stronger redox behavior and oxygen storage capacity of the catalyst, which played an important role in the SCR activities (Li et al., 2016).

\subsubsection{BET analysis}

The BET surface area of a catalyst support plays a significant role in the $\mathrm{NH}_{3}-\mathrm{SCR}$ reaction. Besides, the high BET surface area of the support can improve the catalytic activity considerably 


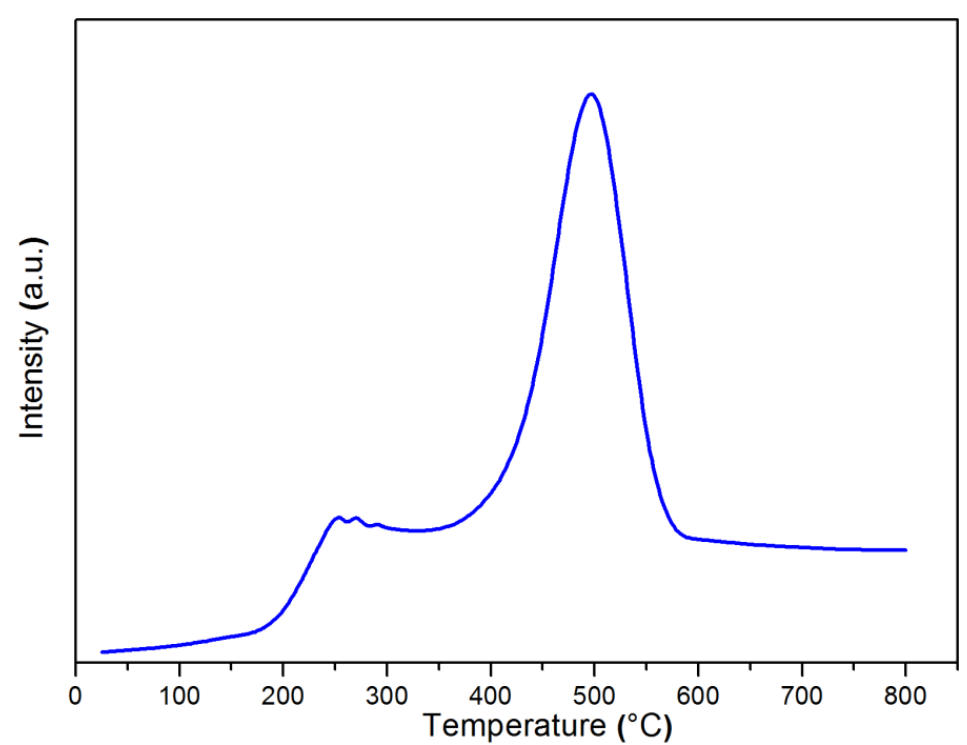

Fig. 4. $\mathrm{H}_{2}$-TPR profiles of the catalysts.

Table 1. BET surface area of the catalysts.

\begin{tabular}{ll}
\hline Catalysts & BET surface area $\left(\mathrm{m}^{2} \mathrm{~g}^{-1}\right)$ \\
\hline ZIF-8 & 1380.73 \\
$0.4 \mathrm{Mn} @ Z I F-8$ & 1623.26 \\
$0.6 \mathrm{Mn} @ Z I F-8$ & 1758.19 \\
$0.8 \mathrm{Mn} @ Z I F-8$ & 1911.34 \\
$1 \mathrm{Mn} @ Z I F-8$ & 1689.17 \\
\hline
\end{tabular}

by means of enhancing the dispersion of active components to avoid aggregation, as well as the transfer of charge (Han et al., 2015; Wang et al., 2013). The BET surface areas of all the samples were listed in Table 1. It can be seen that the high surface area of ZIF-8 would be beneficial to the high $\mathrm{NO}_{\mathrm{x}}$ conversion and the surface area of the samples was increased with the increase of the addition of $\mathrm{Mn}$ species, however, when the addition amount of $\mathrm{Mn}$ species reached $1 \mathrm{~mL}$ (in $\mathrm{Mn}\left(\mathrm{NO}_{3}\right)_{2}$ solution volume), the surface area began to decline. The decrease in specific surface area may be due to the excessive $\mathrm{Mn}$ loading caused formation of large solids and pores clogging of the ZIFs materials. The variation trend of the surface area was in accordance with the SCR activities, which indicated that the BET surface area was an important factor that influenced the SCR activities of the samples.

\subsubsection{Thermogravimetric analysis of Mn@ZIF-8}

As was well known, the MOFs usually have relatively poor thermal stability, yet, the thermal stability of the catalysts has a great impact on the SCR reaction. To investigate the stability of Mn@ZIF-8, the thermal gravimetric analysis was conducted, and the result shown in Fig. 5 exhibited a slightly weight loss of $5 \%$ from room temperature to $450^{\circ} \mathrm{C}$, corresponding to the depletion of guest molecules, mainly $\mathrm{H}_{2} \mathrm{O}$, indicating the structure of Mn@ZIF-8 maintained well under $450^{\circ} \mathrm{C}$, and Mn@ZIF-8 has a high thermal stability. When the temperature was higher than $450^{\circ} \mathrm{C}$, a sharp weight loss of the sample appeared, which could be ascribed to the oxidation of organic ligands and the collapse of the structure of Mn@ZIF-8, which may account for the decrease in activity of the catalysts.

\subsection{The Effect of Loading Amount of Mn Species}

The $\mathrm{NO}_{x}$ conversion of all the catalysts in the range of $200-450^{\circ} \mathrm{C}$ was shown in Fig. 6, from which it could be seen that more Mn species leaded to higher catalytic activity of the samples till the Mn@MOF(0.8) which presented the highest deNO $\mathrm{N}_{\mathrm{x}}$ efficiency compared with the rest 


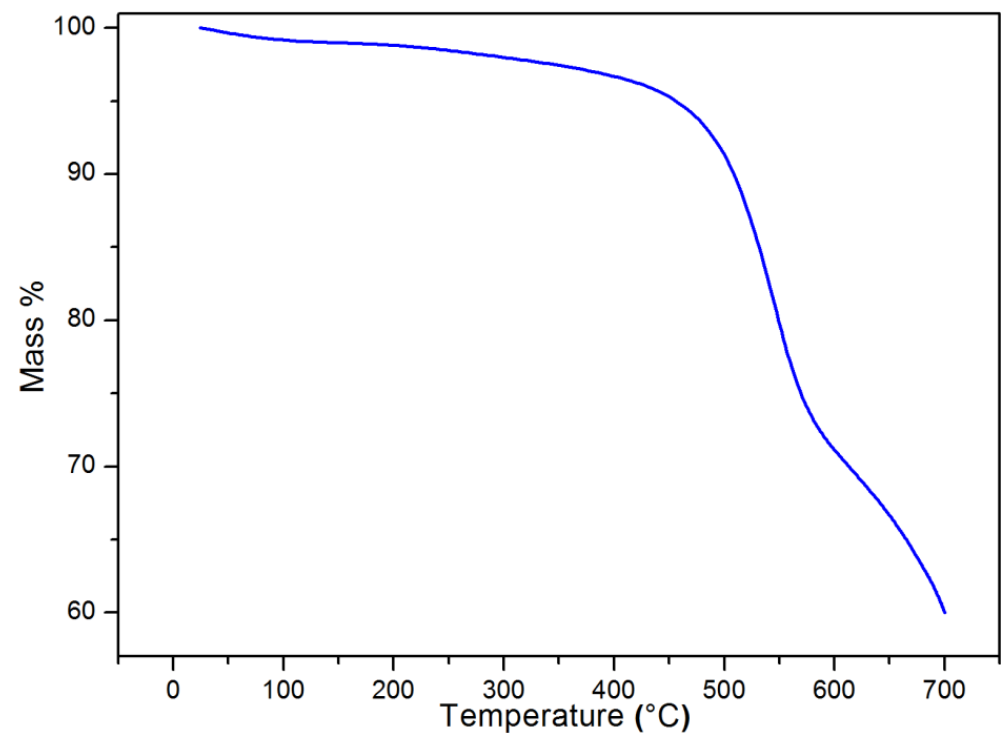

Fig. 5. The TGA curves obtained for the Mn@ZIF-8.
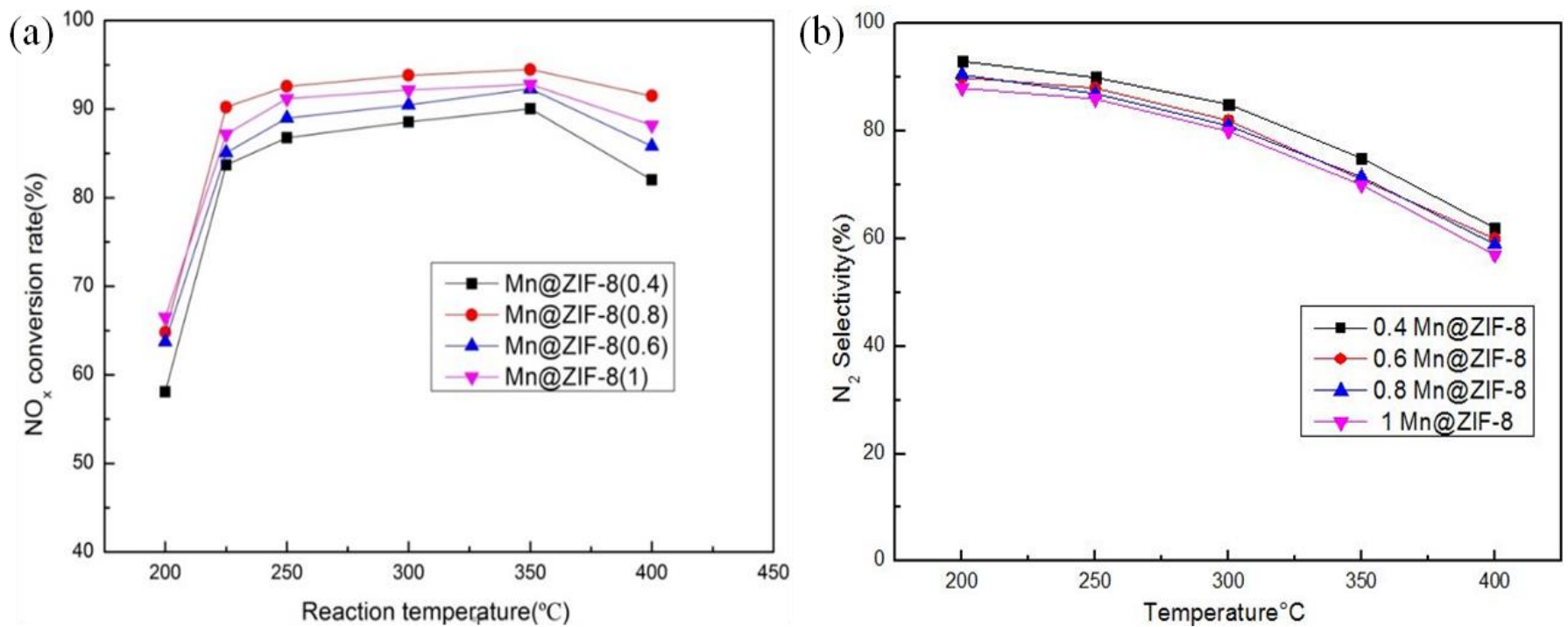

Fig. 6. (a) Catalytic SCR activities and (b) $\mathrm{N}_{2}$ selectivity of the catalysts. Reaction conditions: $\left[\mathrm{NH}_{3}\right]=500 \mathrm{ppm},[\mathrm{NO}]=500 \mathrm{ppm}$, $\left[\mathrm{O}_{2}\right]=3 \%, \mathrm{~N}_{2}=$ balance and total flow rate $=100 \mathrm{~mL} \mathrm{~min}^{-1}$.

Mn loadings. The $\mathrm{NO}_{x}$ conversion of Mn@ZIF-8(0.8) was over $90 \%$ in the range of $225-400^{\circ} \mathrm{C}$, and reached $100 \%$ at $350^{\circ} \mathrm{C}$. However, when the loading amount of $\mathrm{Mn}$ species exceeded $1 \mathrm{~mL}$ (in $\mathrm{Mn}\left(\mathrm{NO}_{3}\right)_{2}$ solution volume), the catalytic activity began to decline, which may be caused by the severe decrease of BET surface area. On the other hand, the $\mathrm{NO}_{\mathrm{x}}$ conversion of all the samples increased with the rising of temperature within $200-350^{\circ} \mathrm{C}$, and when the temperature went up to $400^{\circ} \mathrm{C}$, the $\mathrm{NO}_{x}$ conversion began to decrease, which may be inferred from the TGA analysis that this decreased activity may be caused by the collapse of ZIF-8 framework.

$\mathrm{N}_{2} \mathrm{O}$ is also an important pollutant in the air. Using traditional Mn-based catalysts, a large amount of $\mathrm{N}_{2} \mathrm{O}$ was produced by side reaction and therefore limited its application. In view of this, the formation of $\mathrm{N}_{2} \mathrm{O}$ in the SCR reaction was tested, and the $\mathrm{N}_{2}$ selectivity of catalysts with different loadings was studied. As shown in Fig. 6(b), the $\mathrm{N}_{2} \mathrm{O}$ was formed in all catalysts. With the increase of temperature, ammonia was oxidized to $\mathrm{N}_{2} \mathrm{O}$ gradually, and the nitrogen selectivity of the catalyst decreased continuously. Besides, the nitrogen selectivity of the catalyst decreased when the loading amount of $\mathrm{Mn}$ species increased. Yet the nitrogen selectivity was still over $70 \%$ with higher catalyst activity in the temperature window of $250-350^{\circ} \mathrm{C}$. 


\subsection{Stability Test of Mn@ZIF-8}

Besides, the stability tests of the catalysts at $350^{\circ} \mathrm{C}$ was carried out, and as illustrated in Fig. 7, the $\mathrm{NO}_{x}$ conversion of Mn@ZIF-8 maintained high level after $12 \mathrm{~h}$, presenting a good stability under the identical temperature, which may be ascribed to the porous structures of ZIF- 8 and the strong interaction between Mn species and ZIF-8 (Zhang et al., 2014).

\subsection{Effect of $\mathrm{SO}_{2}$ and $\mathrm{H}_{2} \mathrm{O}$ on Mn@ZIF-8}

As the existence of $\mathrm{H}_{2} \mathrm{O}$ and $\mathrm{SO}_{2}$ is unavoidable in the exhaust, even after desulfurization, the residual $\mathrm{H}_{2} \mathrm{O}$ and $\mathrm{SO}_{2}$ still exert a notable impact on SCR performance. Therefore, the effects of $\mathrm{SO}_{2}$ and $\mathrm{H}_{2} \mathrm{O}$ on the $\mathrm{NO}_{x}$ conversion of Mn@ZIF-8 were investigated. The results shown in Fig. 8 revealed that the $\mathrm{NO}_{x}$ conversion decreased slightly after introducing $200 \mathrm{ppm}$ of $\mathrm{SO}_{2}$, and then reached a relatively steady state. After cutting off the input of $\mathrm{SO}_{2}$, the conversion of $\mathrm{NO}_{\mathrm{x}}$ was gradually restored its original level and remained stable. Hence, it could be concluded that the $\mathrm{Mn} @ \mathrm{ZIF}-8$ had a great resistance to $\mathrm{SO}_{2}$, and the process of $\mathrm{SO}_{2}$ inhibition is reversible. Besides, the negative effect of $\mathrm{SO}_{2}$ on $\mathrm{SCR}$ reaction could be attributed to the following aspects: on one hand, the $\mathrm{SO}_{2}$ would compete with the reactants for the active sites, on the other hand, the formed sulfate depositing (ammonium sulfate and ammonium bisulfate species) would block the active sites (Lu et al., 2015). Yu et al. (2010) proposed that the porous structure was in favor of the great $\mathrm{SO}_{2}$ resistance. The high sulfur resistance of $\mathrm{Mn}$ based catalysts was related to porous silica support (Huang et al., 2008). Thus, it could be inferred that the great $\mathrm{SO}_{2}$ resistance of Mn@ZIF-8 may be ascribed to the porous structure of ZIF-8.

The impact of $\mathrm{H}_{2} \mathrm{O}$ and $\mathrm{SO}_{2}$ was also investigated. The $\mathrm{NO}_{x}$ conversion decreased to $65 \%$ under the coexistence of $\mathrm{H}_{2} \mathrm{O}$ and $\mathrm{SO}_{2}$ and could not recover to the original value after eliminating the $\mathrm{SO}_{2}+\mathrm{H}_{2} \mathrm{O}$ feeding as shown in Fig. 9, which demonstrated that there was a synergistic inhibition effect between $\mathrm{H}_{2} \mathrm{O}$ and $\mathrm{SO}_{2}$, and massive sulfate species and deposition were formed and blocked the active sites.

\section{CONCLUSIONS}

The XRD patterns and SEM image demonstrated that the Mn@ZIF-8 was synthesized successfully, and the Mn species were highly dispersed on ZIF-8. The Mn 2p XPS spectra proved that the $\mathrm{Mn}^{2+}$ and $\mathrm{Mn}^{3+}$ coexisted on the catalysts and played an important role in redox process.

The prepared Mn@ZIF-8 showed an over $90 \%$ NO conversion at the temperatures ranging from $225-400^{\circ} \mathrm{C}$, the excellent catalytic activity may attributed to the huge specific surface area of ZIF-8,

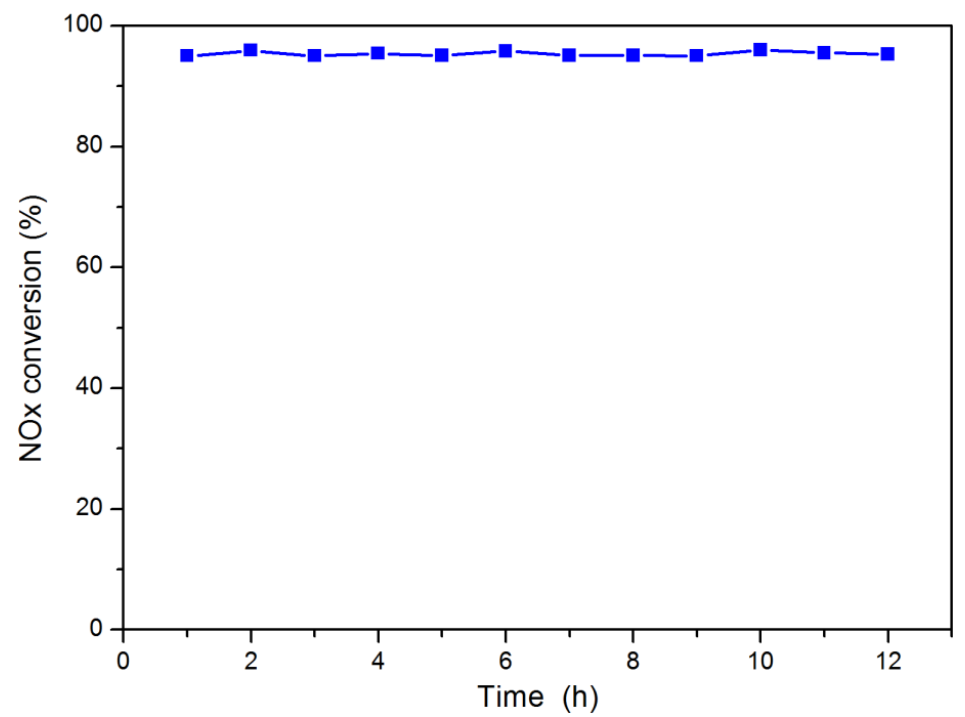

Fig. 7. The catalytic activity of Mn@ZIF-8. Reaction conditions: $\left[\mathrm{NH}_{3}\right]=500$ ppm, [NO] =500 ppm, $\left[\mathrm{O}_{2}\right]=5 \%, \mathrm{~N}_{2}=$ balance and total flowrate $=100 \mathrm{~mL} \mathrm{~min}^{-1}, \mathrm{~T}=350^{\circ} \mathrm{C}$. 


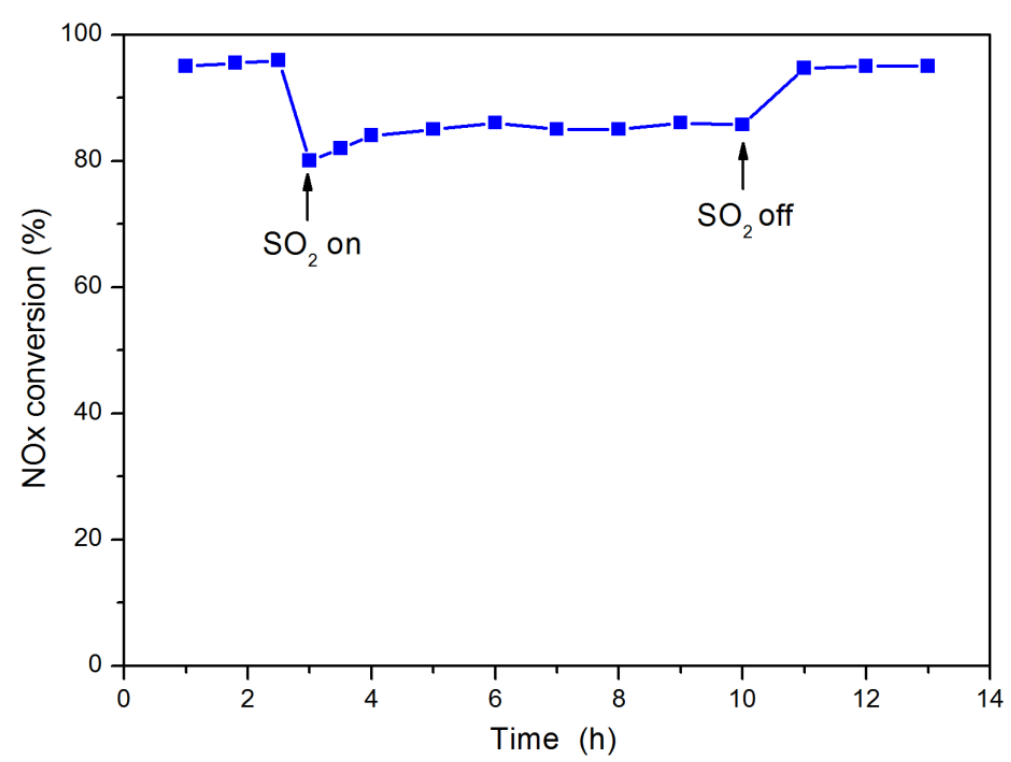

Fig. 8. The effect of $\mathrm{SO}_{2}$ on the SCR activities of Mn@ZIF-8. Reaction conditions: $\left[\mathrm{NH}_{3}\right]=500$ ppm, $[\mathrm{NO}]=500 \mathrm{ppm},\left[\mathrm{SO}_{2}\right]=200 \mathrm{ppm},\left[\mathrm{O}_{2}\right]=5 \%, \mathrm{~N}_{2}=$ balance and total flowrate $=100 \mathrm{~mL} \mathrm{~min}-1, \mathrm{~T}=$ $350^{\circ} \mathrm{C}$.

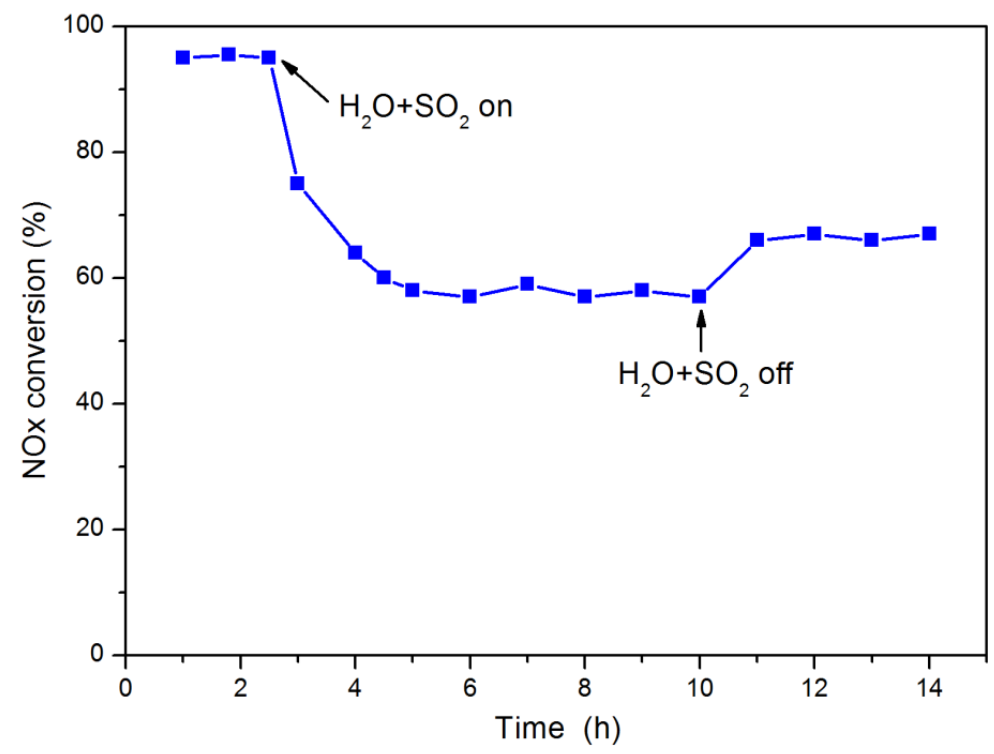

Fig. 9. The effect of $\mathrm{SO}_{2}$ and $\mathrm{H}_{2} \mathrm{O}$ on the SCR activities of Mn@ZIF-8. Reaction conditions: [ $\mathrm{NH}_{3}$ ] $=500 \mathrm{ppm},[\mathrm{NO}]=500 \mathrm{ppm},\left[\mathrm{SO}_{2}\right]=500 \mathrm{ppm},\left[\mathrm{O}_{2}\right]=5 \%,\left[\mathrm{H}_{2} \mathrm{O}\right]=3 \%, \mathrm{~N}_{2}=$ balance and total flowrate $=100 \mathrm{~mL} \mathrm{~min}^{-1}, \mathrm{~T}=350^{\circ} \mathrm{C}$.

as the variation trend of the surface area was in accordance with the SCR activities. Besides, the activity and stability for Mn@ZIF-8 was proved to be ideal after $12 \mathrm{~h}$. Furthermore, the Mn@ZIF-8 exhibited strong tolerance against $\mathrm{SO}_{2}$, which may be ascribed to the porous structure of ZIF-8. It is noteworthy that the catalytic activity of Mn@ZIF-8 was inhibited considerably in the presence of $\mathrm{H}_{2} \mathrm{O}$ and $\mathrm{SO}_{2}$. As a whole, this study demonstrated that the ZIF-8 is a kind of promising support and the use of Mn@ZIF-8 as a novel catalyst for SCR reaction is feasible.

\section{CONFLICTS OF INTEREST}

There are no conflicts to declare. 


\section{ACKNOWLEDGEMENTS}

We would like to extend our sincere appreciation to the support from the National Natural Science Foundation of China (22078176).

\section{REFERENCE}

Atribak, I., López-Suárez, F.E., Bueno-López, A., García-García, A. (2011). New insights into the performance of ceria-zirconia mixed oxides as soot combustion catalysts. Identification of the role of "active oxygen" production. Catal. Today 176, 404-408. https://doi.org/10.1016/j.catt od.2010.11.023

Banerjee, R., Phan, A., Wang, B., Knobler, C., Furukawa, H., O'Keeffe, M. (2008). Highthroughput synthesis of zeolitic imidazolate frameworks and application to $\mathrm{CO}_{2}$ capture. Science 319, 939-943. https://doi.org/ 10.1126/science.1152516

Becerra, M.E., Arias, N.P., Giraldo, O.H., Suárez, F.E.L., Gómez, M.J.I., López, A.B. (2011). Soot combustion manganese catalysts prepared by thermal decomposition of $\mathrm{KMnO}_{4}$. Appl. Catal., B 102, 260-266. https://doi.org/10.1016/j.apcatb.2010.12.006

Brandenberger, S., Kröcher, O., Tissler, A. (2008). The state of the art in selective catalytic reduction of $\mathrm{NO}_{x}$ by ammonia using metal-exchanged zeolite catalysts. Catal. Rev. Sci. Eng. 50, 492-531. https://doi.org/10.1080/01614940802480122

Busca, G., Lietti, L., Ramis, G., Berti, F. (2008). Chemical and mechanistic aspects of the selective catalytic reduction of $\mathrm{NO}_{x}$ by ammonia over oxide catalysts: A review. Appl. Catal. B. 50, 492531. https://doi.org/10.1016/S0926-3373(98)00040-X

Chen, H., Wei, Z., Kollar, M., Gao, F., Wang, Y., Szanyi, J. (2016). No oxidation on zeolite supported cu catalysts: formation and reactivity of surface nitrates. Catal. Today. 267, 17-27. https://doi.org/10.1016/j.cattod.2015.11.039

Cheng, L., Men, Y., Wang, J., Wang, H., An, W., Wang, Y. (2017). Crystal facet-dependent reactivity of $\alpha-\mathrm{Mn}_{2} \mathrm{O}_{3}$ microcrystalline catalyst for soot combustion. Appl. Catal., B 204, 374384.https://doi.org/10.1016/j.apcatb.2016.11.041

Delahay, G., Valade, D., Guzmán-Vargas, A., Coq, B. (2005). Selective catalytic reduction of nitric oxide with ammonia on Fe-ZSM-5 catalysts prepared by different methods. Appl. Catal., B 55, 149-155. https://doi.org/10.1016/j.apcatb.2004.07.009

Du, X., Li, C., Zhao, L., Zhang, J., Lei, G., Sheng, J. (2018). Promotional removal of HCHO from simulated flue gas over Mn-Fe oxides modified activated coke. Appl. Catal., B 232, 37-48. https://doi.org/10.1016/j.apcatb.2018.03.034

Forzatti, P. (2001). Present status and perspectives in de-NOx SCR catalysis. Appl. Catal., A 222, 221-236. https://doi.org/10.1016/s0926-860x(01)00832-8

Gao, F., Mei, D., Wang, Y., Szanyi, J., Peden, C. (2017). Selective catalytic reduction over Cu/SSZ13: Linking homo- and heterogeneous catalysis. J. Am. Chem. Soc. 139, 4935-4942. https://doi.org/10.1021/jacs.7b01128

Gee, J.A., Chung, J., Nair, S., Sholl, D.S. (2013). Adsorption and diffusion of small alcohols in zeolitic imidazolate frameworks ZIF-8 and ZIF-90. J. Phys. Chem. C 117, 3169-3176. https://doi.org/10.1021/jp312489w

Guo, X., Li, J., Zhou, R. (2016). Catalytic performance of manganese doped $\mathrm{CuO}-\mathrm{CeO}_{2}$ catalysts for selective oxidation of CO in hydrogen-rich gas. Fuel 163, 56-64. https://doi.org/10.1016/j. fuel.2015.09.043

Han, J., Wang, D., Du, Y., Xi, S., Hong, J., Yin S., Chen, Z., Zhou., T.H. (2015) Metal-organic framework immobilized cobalt oxide nanoparticles for efficient photocatalytic water oxidation. J. Mater. Chem. A 3, 20607-20613. https://doi.org/10.1039/c5ta04675k

Huang, J., Tong, Z., Yan, H., Zhang, J. (2008). Selective catalytic reduction of NO with $\mathrm{NH}_{3}$ at low temperatures over iron and manganese oxides supported on mesoporous silica. Appl. Catal., B 78, 309-314. https://doi.org/10.1016/j.apcatb.2007.09.031

Huang, X., Lin, Y., Zhang, J., Chen X. (2010). Ligand-directed strategy for zeolite-type metalorganic frameworks: Zinc(II) imidazolates with unusual zeolitic topologies. Angew. Chem. Int. Ed. 45, 1557-1559. https://doi.org/10.1002/anie.200503778 
Küsgens, P., Rose, M., Senkovska, I., Fröde, H., Henschel, A., Siegle, S. (2009). Characterization of metal-organic frameworks by water adsorption. Microporous Mesoporous Mater. 120, 325-330. https://doi.org/10.1016/j.micromeso.2008.11.020

Lee, J., Farha, O., Roberts, J., Scheidt, K., Hupp, J. (2009). ChemInform abstract: Metal-organic framework materials as catalysts. Chemlnform 40 https://doi.org/10.1002/chin.200933268

Li, C., Tang, X., Yi, H., Wang, L., Cui, X., Chu, C. (2017). Rational design of template-free $\mathrm{MnO}_{\mathrm{x}^{-}}$ $\mathrm{CeO}_{2}$ hollow nanotube as De-NOx catalyst at low temperature. Appl. Surf. Sci. 428, 924-932. https://doi.org/10.1016/j.apsusc.2017.09.131

Li, D., Yang, G., Li, P., Wang, J., Zhang, P. (2016). Promotion of formaldehyde oxidation over Ag catalyst by $\mathrm{Fe}$ doped $\mathrm{MnO}_{x}$ support at room temperature. Cataly. Today. 277, 257-265. https://doi.org/10.1016/j.cattod.2016.02.040

Li, L., Yan, N., Zan, Q., Qiao, S., Yang, S., Guo, Y. (2010). Catalytic oxidation of elemental mercury over the modified catalyst $\mathrm{Mn} / \alpha-\mathrm{Al}_{2} \mathrm{O}_{3}$ at lower temperatures. Environ. Sci. Technol. 44, 42631. https://doi.org10.1021/es9021206

Liu, S., Wu, X., Duan, W., Min, L., Lee, H.R. (2012). Combined promoting effects of platinum and $\mathrm{MnO}_{x}-\mathrm{CeO}_{2}$ supported on alumina on $\mathrm{NO}_{x}$-assisted soot oxidation: thermal stability and sulfur resistance. Chem. Eng. J. 203, 25-35. https://doi.org/10.1016/j.cej.2012.06.090

Lu, Q., Meng, J., Pang, D., Zhang, C., Feng, O. (2015). Reaction and characterization of Co and Ce doped $\mathrm{Mn} / \mathrm{TiO}_{2}$ catalysts for low-temperature SCR of $\mathrm{NO}$ with $\mathrm{NH}_{3}$. Catal. Lett. 2145, 15001509. https://doi.org/10.1007/s10562-015-1556-x

Min, K., Park, E.D., Ji, M.K., Yie, J.E. (2007). Manganese oxide catalysts for $\mathrm{NO}_{x}$ reduction with $\mathrm{NH}_{3}$ at low temperatures. Appl. Catal., A 327, 261-269. https://doi.org/10.1016/j.apcata.2007.05.024

Nguyen, L., Ky, L., Phan, N. (2012). A zeolite imidazolate framework ZIF-8 catalyst for friedelcrafts acylation. Chin. J. Catal. 33, 688-696. https://doi.org/10.1016/S1872-2067(11)60368-9

Niu, Y., Tong, S., Hui, S., Zhang, X., Shui, W. (2016). Synergistic removal of NO and $\mathrm{N}_{2} \mathrm{O}$ in lowtemperature SCR process with $\mathrm{MnO}_{x} / \mathrm{Ti}$ based catalyst doped with $\mathrm{Ce}$ and V. Fuel 185, 316322. https://doi.org/10.1016/j.fuel.2016.07.122

Park, K.S., Ni, Z., Côté, A.P., Choi, J.Y., Huang, R., Uribe-Romo, F.J., Chae, H.K., O’Keeffe, M., Yaghi, O.M. (2006). Exceptional chemical and thermal stability of zeolitic imidazolate frameworks. PNAS 103, 10186-10191. https://doi.org/10.1073/pnas.0602439103

Park, K.H., Sang, M., Kim, S., Dong, W. (2013). Reversibility of $\mathrm{Mn}$ valence state in $\mathrm{MnO}_{\mathrm{x}} / \mathrm{TiO}_{2}$ catalysts for low-temperature selective catalytic reduction for no with $\mathrm{NH}_{3}$. Catal. Lett. 143, 246-253. https://doi.org/10.1007/s10562-012-0952-8

Peng, S., Guo, R.T., Liu, S.M., Wang, S.X., Li, M.Y. (2016). The enhanced performance of $\mathrm{MnO}_{x}$ catalyst for $\mathrm{NH}_{3}-\mathrm{SCR}$ reaction by the modification with Eu. Appl. Catal., A 531, 129-138. https://doi.org/10.1016/j.apcata.2016.10.027

Qi, G., Yang, R.T. (2003a). A superior catalyst for low-temperature NO reduction with $\mathrm{NH}_{3}$. Cheminform 34, 848-849. https://doi.org/10.1039/b212725c

Qi, G., Yang, R.T. (2003b). Performance and kinetics study for low-temperature SCR of NO with $\mathrm{NH}_{3}$ over $\mathrm{MnO}_{\mathrm{x}}-\mathrm{CeO}_{2}$ catalyst. J. Catal. 217, 434-441. https://doi.org/10.1016/S00219517(03)00081-2

Qi, G., Yang, R., Chang, R. (2004). $\mathrm{MnO}_{x}-\mathrm{CeO}_{2}$ mixed oxides prepared by co-precipitation for selective catalytic reduction of $\mathrm{NO}$ with $\mathrm{NH}_{3}$ at low temperatures. Appl. Catal., B 51, 93-106. https://doi.org/10.1016/j.apcatb.2004.01.023

Qi, G., Yang, R.T., Thompson, L. (2004). Catalytic reduction of nitric oxide with hydrogen and carbon monoxide in the presence of excess oxygen by Pd supported on pillared clays. Appl. Catal., A 259, 261-267. https://doi.org/10.1016/j.apcata.2003.09.040

Shen, Z., Hu, F.Y., Li, J. (2016). Hierarchical core-shell $\mathrm{Al}_{2} \mathrm{O}_{3} @ \mathrm{Pd}-\mathrm{Co} A \mathrm{OO}$ microspheres for lowtemperature toluene combustion. ACS Catal. 6, 3433-3441. https://doi.org/3433-3441.10.10 21/acscatal.6b00144

Singoredjo, L., Korver, R., Kapteijn, F., Moulijn, J. (2010). Alumina supported manganese oxides for the low-temperature selective catalytic reduction of nitric oxide with ammonia. Appl. Catal. B 24, 297-316. https://doi.org/10.1002/chin.199311017

Sun, C., Liu, H., Chen, W., Chen, D., Yu, S., Liu, A. (2018). Insights into the Sm/Zr co-doping effects on $\mathrm{N}_{2}$ selectivity and $\mathrm{SO}_{2}$ resistance of a $\mathrm{MnO}_{x}-\mathrm{TiO}_{2}$ catalyst for the $\mathrm{NH}_{3}-\mathrm{SCR}$ reaction. Chem. Eng. J. 347, 27-40. https://doi.org/10.1016/j.cej.2018.04.029 
Tran, U.P.N., Le, K.K.N., Phan, N.T.S. (2011). Expanding applications of metal-organic frameworks: zeolite imidazolate framework ZIF-8 as an efficient heterogeneous catalyst for the knoevenagel reaction. ACS Catal. 1, 120-127. https://doi.org/10.1021/cs1000625

Twigg, M.V. (2007). Progress and future challenges in controlling automotive exhaust gas emissions. Appl. Catal., B 70, 2-15. https://doi.org/10.1016/j.apcatb.2006.02.029

Venna, S.R., Jasinski, J.B., Carreon, M.A. (2010). Structural evolution of zeolitic imidazolate framework-8. J. Am. Chem. Soc. 132, 18030. https://doi.org/10.1021/ja109268m

Wang, P., Sun, H., Quan, X., Chen, S. (2016). Enhanced catalytic activity over Mil-100(Fe) loaded ceria catalysts for the selective catalytic reduction of $\mathrm{NO}_{x}$ with $\mathrm{NH}_{3}$ at low temperature. J. Hazard. Mater. 301, 512-521. https://doi.org/10.1016/j.jhazmat.2015.09.024

Wang, X., Zheng, Y., Lin, J. (2013). Highly dispersed Mn-Ce mixed oxides supported on carbon nanotubes for low-temperature no reduction with $\mathrm{NH}_{3}$. Catal. Commun. 37, 96-99. https://doi.org/10.1016/j.catcom.2013.03.035

Wei, Y., Chen, Y., Wang, R. (2018). Rare earth salt of 12-tungstophosphoric acid supported on iron oxide as a catalyst for selective catalytic reduction of $\mathrm{NO}_{\mathrm{x}}$. Fuel Process. Technol. 178, 262-270. https://doi.org/10.1016/j.fuproc.2018.06.001

Wu, Z., Jiang, B., Liu, Y., Zhao, W., Guan, B. (2007). Experimental study on a low-temperature SCR catalyst based on $\mathrm{MnO}_{x} / \mathrm{TiO}_{2}$ prepared by sol-gel method. J. Hazard. Mater. 145, 488494. https://doi.org/10.1016/j.jhazmat.2006.11.045

Yang, S., Qi, F., Xiong, S., Hao, D., Li, J. (2016). $\mathrm{MnO}_{x}$ supported on Fe-Ti spinel: A novel Mn based low temperature SCR catalyst with a high $\mathrm{N}_{2}$ selectivity. Appl. Catal., B 181, 570-580. https://doi.org/10.1016/j.apcatb.2015.08.023

Yi, L., Zheng, L., Mnichowicz, B., Harinath, A., Li, H., Bahrami, B. (2016). Chemical deactivation of commercial vanadium SCR catalysts in diesel emission control application. Chem. Eng. J. 287, 680-690. https://doi.org/10.1016/j.cej.2015.11.043

Yu, J., Guo F., Wang, Y., Zhu, J., Liu, Y., Su, F., Gao, S., Xu, G. (2010). Sulfur poisoning resistant mesoporous $\mathrm{Mn}$-base catalyst for low-temperature SCR of $\mathrm{NO}$ with $\mathrm{NH}_{3}$. Appl. Catal., B 95, 160-168. https://doi.org/10.1016/j.apcatb.2009.12.023

Zhang, L., Shi, L., Huang, L., Zhang, J., Ga, R., Zhang, D. (2014). Rational design of highperformance $\mathrm{DeNO}_{\mathrm{x}}$ catalysts based on $\mathrm{Mn}_{\mathrm{x}} \mathrm{CO}_{3-\mathrm{x}} \mathrm{O}_{4}$ nanocages derived from metal-organic frameworks. ACS Catal. 4, 1753-1763. https://doi.org/10.1021/cs401185c

Zhang, S., Zhao, Y., Yang, J., Zhang, J., Zheng, C. (2018). Fe-modified $\mathrm{MnO}_{x} / \mathrm{TiO}_{2}$ as the SCR catalyst for simultaneous removal of $\mathrm{NO}$ and mercury from coal combustion flue gas. Chem. Eng. J. 348, 618-629. https://doi.org/10.1016/j.cej.2018.05.037

Zhang, W., Shi, Y., Li, C., Zhao, Q., Li, X. (2016). Synthesis of bimetallic MOFs MIL-100(Fe-Mn) as an efficient catalyst for selective catalytic reduction of $\mathrm{NO}_{x}$ with $\mathrm{NH}_{3}$. Catal. Lett. 146, 19561964. https://doi.org/10.1007/s10562-016-1840-4

Zhang, X., Shen, B., Zhang, X., Wang, F., Chi, G., Si, M. (2017). A comparative study of manganese-cerium doped metal-organic frameworks prepared via impregnation and in situ methods in the selective catalytic reduction of NO. RSC Adv. 7, 5928-5936. https://doi.org/ 10.1039/c6ra25413f

Zhao, L., Li, C., Li, S.,Wang, Y., Zhang, J., Wang, T., Zeng, G. (2016). Simultaneous removal of elemental mercury and $\mathrm{NO}$ in simulated flue gas over $\mathrm{V}_{2} \mathrm{O}_{5} / \mathrm{ZrO}_{2}-\mathrm{CeO}_{2}$ catalyst. Appl. Catal., B 198, 420-430. https://doi.org/10.1016/j.apcatb.2016.05.079 